\title{
Novel cardioprotective effects of tetrahydrobiopterin after anoxia and reoxygenation: Identifying cellular targets for pharmacologic manipulation
}

\author{
Subodh Verma, MD, PhD \\ Andrew Maitland, MD \\ Richard D. Weisel, MD \\ Paul W. M. Fedak, MD \\ Neil C. Pomroy, MSc \\ Shu-Hong Li, MSc \\ Donald A. G. Mickle, MD \\ Ren-Ke Li, MD, PhD \\ Vivek Rao, MD, PhD
}

\begin{abstract}
From the Division of Cardiac Surgery, Toronto General Hospital, Toronto, Ontario, Canada. ischemia-reperfusion and (2) an in vitro human ventricular heart cell model of simulated ischemia-reperfusion. Measures of endothelial function, oxidant production, cell survival, and cardiac function were used to assess outcome.
\end{abstract}

Supported by operating grants from the Heart and Stroke Foundation of Canada (R.D.W., V.R.) and Canadian Diabetes Association (R.D.W., V.R.). S.V. and P.W.M.F. are Fellows of the Canadian Institutes for Health Research (formerly MRC) and the Heart and Stroke Foundation of Canada. R.K.L. is a Career Investigator of the Heart and Stroke Foundation of Ontario. S.V. was selected as the Paul C. Samson Award Finalist (2001) for this research.

Read at the Twenty-seventh Annual Meeting of The Western Thoracic Surgical Association, San Diego, Calif, June 20-23, 2001.

Received for publication June 28, 2001; revisions requested Sept 18, 2001; revisions received Oct 12, 2001; accepted for publication Oct 24, 2001.

Address for reprints: Richard D. Weisel, MD (E-mail: richard.weisel@uhn.on.ca), or Subodh Verma, MD, PhD, Division of Cardiac Surgery, Toronto General Hospital, 14-215, 200 Elizabeth St, Toronto, Ontario M5G 2C4, Canada.

J Thorac Cardiovasc Surg 2002;123: 1074-83

Copyright (C) 2002 by The American Association for Thoracic Surgery

$0022-5223 / 2002 \$ 35.00+0 \quad \mathbf{1 2 / 6 / 1 2 1 6 8 7}$

doi: $10.1067 / \mathrm{mtc} .2002 .121687$
Objectives: Contemporary cardioprotective strategies to prevent perioperative ischemia-reperfusion injury have focused on the L-arginine nitric oxide pathway. Tetrahydrobiopterin is an absolute cofactor required for the enzyme nitric oxide synthase and is thus a critical determinant of nitric oxide production. We hypothesized that ischemia-reperfusion results in diminished levels of tetrahydrobiopterin, which might represent a key cellular defect underlying endothelial and myocyte dysfunction after ischemia-reperfusion. To this aim, we examined the effects of tetrahydrobiopterin supplementation in (1) an in vivo experimental model of global

Methods: In study 1 Wistar rats were divided into one of 2 groups $(\mathrm{n}=10$ per group). One group received tetrahydrobiopterin $\left(25 \mathrm{mg} \cdot \mathrm{kg}^{-1} \cdot \mathrm{d}^{-1}\right.$ for 7 days), and the other group served as the control group. Hearts were subjected to 30 minutes of ischemia followed by 30 minutes of reperfusion, and left ventricular developed pressure, left ventricular systolic pressure, and left ventricular end-diastolic pressure were determined by using the modified Langendorff technique. In study 2 we quantitated myocardial malondialdehyde, a marker of lipid peroxidation, in ventricular tissues from both groups of animals using butanol phase extraction and spectrophotometric analysis. In study 3 coronary vascular responses were determined in vascular segments of the left coronary artery in both groups of animals after ischemia-reperfusion. Endothelium-dependent and endothelium-independent vasodilatation to acetylcholine and sodium nitroprusside, respectively, were compared between groups. In study 4, using a human ventricular heart cell model of simulated ischemia-reperfusion, we studied the effects of tetrahydrobiopterin (20 $\mu \mathrm{mol} / \mathrm{L}$ ) on cellular injury (as assessed by means of trypan blue uptake).

Results: After ischemia-reperfusion, myocardial dysfunction was evidenced by a decrease in left ventricular developed pressure and an increase in left ventricular enddiastolic pressure $(P=.01$ compared with baseline). Hearts from tetrahydrobiopterintreated rats exhibited protection against ischemia-reperfusion injury (left ventricular developed pressure: $74 \pm 4$ vs control $42 \pm 8 \mathrm{~mm} \mathrm{Hg}, P=.01$; left ventricular end-diastolic pressure: $12 \pm 3$ vs $34 \pm 7 \mathrm{~mm} \mathrm{Hg}, P=.01$ ). Furthermore, tetrahydrobiopterin treatment attenuated the rise in malondialdehyde levels after ischemia-reperfusion $(P=.01)$. After reperfusion, coronary endothelial function to acetylcholine was attenuated ( $P=.003$ vs sham-treated mice), whereas responses to 
sodium nitroprusside remained unchanged. Tetrahydrobiopterin-treated rats exhibited an improvement in acetylcholine-mediated vasorelaxation $(P=.01$ vs ischemiareperfusion group). Cellular injury, as assessed by means of trypan blue uptake, was higher in human ventricular heart cells subjected to simulated ischemia-reperfusion; this effect was prevented with tetrahydrobiopterin treatment $(P=.001)$.

Conclusions: Supplemental tetrahydrobiopterin provides a novel cardioprotective effect on left ventricular function, endothelial-vascular reactivity, oxidative damage, and cardiomyocyte injury after ischemia-reperfusion injury and might represent an important cellular target for future operative myocardial protection strategies.

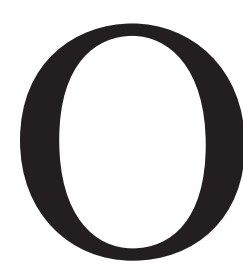

ne of the most common and predictable forms of ischemia-reperfusion (I/R) injury occurs during cardiac operations, when the heart is arrested for surgical intervention and subsequently reperfused by removal of the aortic crossclamp. Devising pharmacologic strategies to counter perioperative I/R injury might serve to restore functional integrity during cardioplegic arrest. Contemporary cardioprotective strategies to prevent I/R injury have focused on the L-argininenitric oxide (NO) pathway. Tetrahydrobiopterin $\left(\mathrm{BH}_{4}\right)$ is an essential cofactor required for nitric oxide synthase (NOS), and hence NO production is critically dependent on the presence of adequate amounts of $\mathrm{BH}_{4} \cdot{ }^{1-4}$ Diminished levels of $\mathrm{BH}_{4}$ might lead to an uncoupling of NOS, with the resultant production of reactive oxygen species instead of NO. The beneficial effects of $\mathrm{BH}_{4}$ supplementation have been recently confirmed in a variety of cardiovascular disease states. ${ }^{1-3,5}$

In the present study we hypothesized that I/R injury results in diminished bioavailability of $\mathrm{BH}_{4}$, which might lead to endothelial and myocyte dysfunction. To this aim, we examined the effects of $\mathrm{BH}_{4}$ treatment on cardiac dysfunction, impaired endothelium-dependent vasodilatation, and lipid peroxidation in a model of global I/R. To examine whether $\mathrm{BH}_{4}$ exerts direct cardioprotective effects (independent of other cell types), we studied the effects of this cofactor on cellular injury in a human ventricular cardiomyocyte model of simulated I/R. We herein report, for the first time, novel cardioprotective effects of $\mathrm{BH}_{4}$ on the aforementioned pathways, which suggest that $\mathrm{BH}_{4}$ might represent an important cellular target for future operative myocardial protection strategies.

\section{Materials and Methods}

\section{Animals}

Male Wistar rats (200-250 g) were divided into one of 2 groups ( $\mathrm{n}=10$ per group). Experiments were performed in accordance with the Canadian Animal Care Guidelines. The first group of rats was treated with $\mathrm{BH}_{4}\left(25 \mathrm{mg} \cdot \mathrm{kg}^{-1} \cdot \mathrm{d}^{-1}\right.$ administered intrave- nously) for 7 days, and the second group of rats received saline injections. Similar doses have been used in an experimental model of porcine lung transplantation. ${ }^{3}$ After treatment, hearts were excised for isolated perfusion study by using the modified Langendorff technique.

\section{Isolated Perfused Heart Study}

All rats were anesthetized with sodium pentobarbital $(60 \mathrm{mg} / \mathrm{kg}$ administered intraperitoneally), and the hearts were removed and placed in ice-cold Krebs buffer with the following composition: $120 \mathrm{mmol} / \mathrm{L} \mathrm{NaCl}, 4.7 \mathrm{mmol} / \mathrm{L} \mathrm{KCl}, 1.2 \mathrm{mmol} / \mathrm{L} \mathrm{KH}_{2} \mathrm{PO}_{4}, 1.2$ $\mathrm{mmol} / \mathrm{L} \mathrm{MgSO}_{4}, 1.25 \mathrm{mmol} / \mathrm{L} \mathrm{CaCl}_{2}, 25 \mathrm{mmol} / \mathrm{L} \mathrm{NaHCO}_{3}$, and $11 \mathrm{mmol} / \mathrm{L}$ glucose $(\mathrm{pH}$ 7.4). The hearts were then transferred to the isolated perfusion apparatus and perfused in a retrograde fashion through the aorta with oxygenated $\left(95 \% \mathrm{O}_{2}\right.$ and $\left.5 \% \mathrm{CO}_{2}\right)$ Krebs buffer maintained at $37^{\circ} \mathrm{C}$. The hearts were electrically stimulated at a rate of 300 beats/min and perfused at a constant flow rate of $10 \mathrm{~mL} / \mathrm{min}$. A water-filled latex balloon was inserted into the left ventricle through the left atrium and connected to a pressure transducer (Gould Satham) for the measurement of left ventricular end-diastolic pressure (LVEDP), left ventricular systolic pressure, and left ventricular developed pressure (LVDP; ie, left ventricular systolic pressure minus LVEDP). LVEDP during the phase of equilibration was set between 5 and $8 \mathrm{~mm} \mathrm{Hg}$.

Four hearts from the saline-treated group were continuously perfused with Krebs buffer for 90 minutes and served as the sham control group. Hearts from the other rats were subjected to 30 minutes of global ischemia followed by 30 minutes of reperfusion. The Krebs buffer was supplemented with $\mathrm{BH}_{4}(20 \mu \mathrm{mol} / \mathrm{L})$ during the assessment of the treated group. After completion of the experiment, the hearts were frozen in liquid nitrogen for the assessment of malondialdehyde (MDA), a marker of lipid peroxidation, as described below.

\section{Determination of MDA Levels in Myocardium}

MDA levels in the myocardium were measured in duplicate by using a modification of the method of Ohkawa and associates, ${ }^{6}$ as described by Chen and colleagues. ${ }^{7}$ Ventricular tissue was dissected and homogenized. The assay mixture consisted of $0.1 \mathrm{~mL}$ of the tissue homogenate, $0.4 \mathrm{~mL}$ of $0.9 \% \mathrm{NaCl}, 0.5 \mathrm{~mL}$ of $3 \%$ sodium dodecylsulfate, and $3 \mathrm{~mL}$ of thiobarbituric acid and acetic acid and was heated for 75 minutes at $95^{\circ} \mathrm{C}$. Thereafter, $1 \mathrm{~mL}$ of cold $0.9 \% \mathrm{NaCl}$ was added to the mixture, which was cooled and 


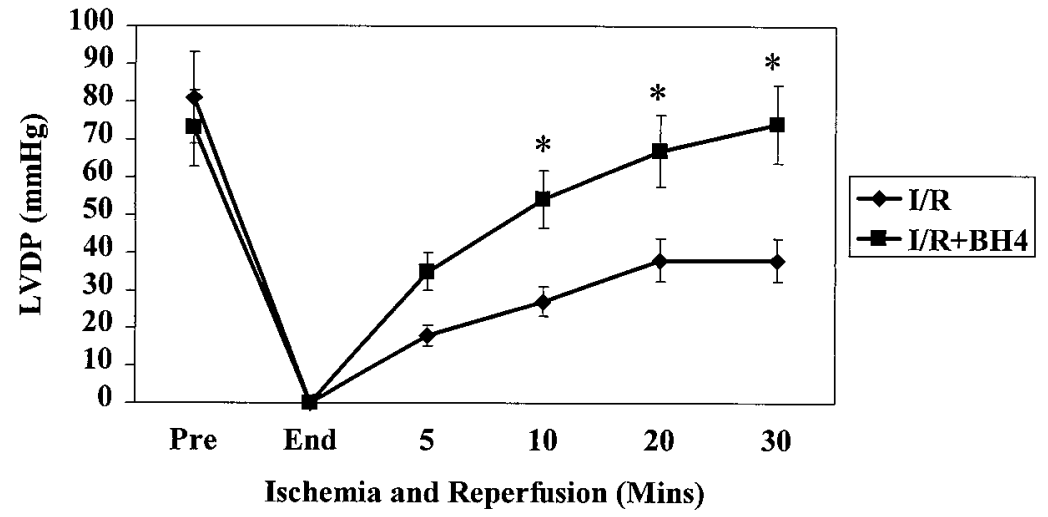

Figure 1. LVDP after 30 minutes of global ischemia and 30 minutes of reperfusion. I/R caused marked cardiac dysfunction. $\mathrm{BH}_{4}$ supplementation improved functional recovery after $\mathrm{I} / \mathrm{R}$. ${ }^{*} \boldsymbol{P}=.01 \mathrm{versus} \mathrm{I} / \mathrm{R}$.

extracted with $5 \mathrm{~mL}$ of $n$-butanol. After centrifugation at $3000 \mathrm{rpm}$ for 15 minutes, the butanol phase was assayed spectrophotometrically at $532 \mathrm{~nm}$. Tetrahmethoxypropane (in amounts of $0,0.1,0.2$, $0.4,0.8$, and $1.0 \mathrm{nmol}$ ) served as the external standard. MDA levels in myocardium were expressed as micromoles per gram of tissue. $^{7}$

\section{Endothelial Function Assessment}

In a separate experiment we examined the effects of $\mathrm{BH}_{4}$ treatment on endothelium-dependent and endothelium-independent vascular relaxation after global I/R injury. Briefly, after I/R, the left coronary artery was dissected under a microscope, and vascular segments (1-2 $\mathrm{mm}$ in length) were used for the assessment of in vitro vascular function by using a small-vessel myograph for isometric tension recording. Care was taken during dissection and mounting to avoid damage to the endothelium. Briefly, after stabilization, the vessels were stimulated according to the following protocol: (1) cumulative dose-response curve (DRC) to phenylephrine $\left(10^{-9}\right.$ $\left.10^{-5} \mathrm{~mol} / \mathrm{L}\right)$; (2) DRC to acetylcholine $\left(10^{-9}-10^{-5} \mathrm{~mol} / \mathrm{L}\right)$ in rings precontracted with the effective dose causing $75 \%$ maximum contraction $\left(\mathrm{ED}_{75}\right)$ of phenylephrine; and (3) DRC to sodium nitroprusside (SNP; $10^{-11}-10^{-6} \mathrm{~mol} / \mathrm{L}$ ) in rings precontracted with the $\mathrm{ED}_{75}$ of phenylephrine. The percentage of maximum relaxation was compared between groups.

\section{Human Heart Cell Model of I/R}

Our method of culturing heart cells from human ventricular biopsy specimens has been previously described in detail. ${ }^{8,9}$ In brief, 5- to 20-mg biopsy specimens were obtained from the right ventricular outflow tract of patients undergoing elective operations for tetralogy of Fallot. The average age of the patients ranged from 4 to 14 years. After digestion with trypsin $(0.2 \%)$ and collagenase $(0.1 \%)$, the separated cells were seeded onto cell-culture dishes and cultured at $37^{\circ} \mathrm{C}$ and $5 \% \mathrm{CO}_{2}$ in Iscove's modified Dulbecco's medium with $10 \%$ fetal bovine serum, $100 \mathrm{U} / \mathrm{mL}$ penicillin, 100 $\mu \mathrm{g} / \mathrm{mL}$ streptomycin, and $0.1 \mathrm{mmol} / \mathrm{L} \beta$-mercapthoethanol. Purification was achieved by using a dilution cloning technique. Enzymatically isolated cells were seeded at a low density to enable morphologic identification of individual cardiomyocytes and sep- aration from contaminating cell types. Single cardiomyocyte colonies were then transferred to a separate culture dish. The use of cardiomyocytes facilitates examining the contribution of I/R independent of other cell types, such as endothelial cells or fibroblasts. Our technique of simulated I/R has also been described in detail previously. ${ }^{8,9}$ In brief, after 30 minutes of stabilization in $10 \mathrm{~mL}$ of normoxic phosphate-buffered saline (PBS), ischemia was simulated by exposing the cells to a low volume $(1.6 \mathrm{~mL})$ of anoxic PBS at $37^{\circ} \mathrm{C}$ for 90 minutes. During this period, the cells were placed in an airtight Plexiglas chamber, which was continuously flushed with $100 \%$ nitrogen to maintain anoxic conditions. Ischemia was followed by a reperfusion period in which the cells were exposed to $10 \mathrm{~mL}$ of normoxic PBS at $37^{\circ} \mathrm{C}$ for 30 minutes. Both low-volume and anoxic conditions were used to mimic ischemia. The volume of anoxic perfusate used $(1.6 \mathrm{~mL})$ was the minimum volume required to coat the cellular monolayer for the prevention of cellular dehydration during the ischemic period. To verify the presence of anoxia, we placed $2 \mathrm{~mL}$ of anoxic PBS in a center dish within the sealed chamber and tested at the termination of each ischemic period to ensure a $\mathrm{PO}_{2}$ of $0 \mathrm{~mm} \mathrm{Hg}$. Anoxic $\mathrm{PBS}$ was prepared by bubbling with $5 \% \mathrm{CO}_{2}$ and $95 \%$ nitrogen that had first been passed through an oxygen trap $\left(1 \%\right.$ wt/vol $\mathrm{NaHSO}_{3}$ in deionized water). The solution (monitored with a blood gas analyzer) was degassed until a $\mathrm{Po}_{2}$ of $0 \mathrm{~mm} \mathrm{Hg}$ and a $\mathrm{PCO}_{2}$ of less than $10 \mathrm{~mm} \mathrm{Hg}$ were achieved. A pH of $7.4 \pm 0.05$ and an osmolality of $290 \pm 20 \mathrm{mOsm} / \mathrm{L}$ were ensured before use. For the assessment of cellular injury, cells were stained with trypan blue at the end of the reperfusion period (after 150 minutes of incubation for the nonischemic groups). Injured cells were unable to exclude the large-molecular-weight dye and stained blue. The above protocol was repeated in the presence of $\mathrm{BH}_{4}(20 \mu \mathrm{mol} / \mathrm{L})$ added before reperfusion. A single blinded observer performed cell counts.

\section{Statistical Analysis}

Data are presented as means \pm SEM. Data were compared by using a 2-way analysis of variance followed by the Newman-Keuls test for post hoc comparisons. 


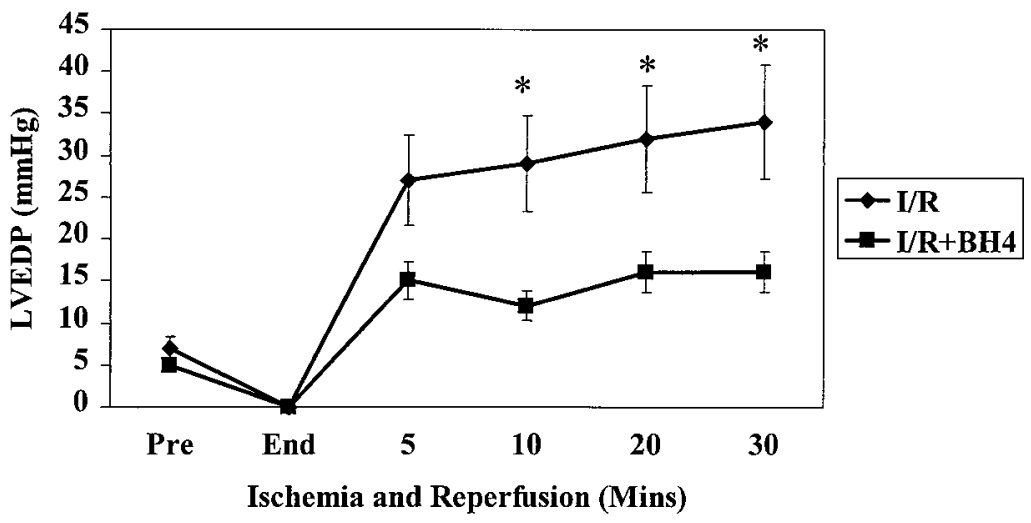

Figure 2. LVEDP after 30 minutes of global ischemia and 30 minutes of reperfusion. I/R caused an increase in LVEDP. $\mathrm{BH}_{4}$ supplementation improved functional recovery after $\mathrm{I} / \mathrm{R}$, as evidenced by a significantly lower increase in LVEDP after $\mathbf{I} / \mathbf{R}$. ${ }^{*} \boldsymbol{P}=.01$ versus $\mathrm{I} / \mathrm{R}$.

\section{Results}

\section{Cardiac Function Assessment}

The baseline values of LVDP and LVEDP did not differ between the groups at baseline $(P>.2)$. The sham group exhibited no changes in cardiac function during the 90minute perfusion period $(P>.2)$. After 30 minutes of global ischemia and 30 minutes of reperfusion, the hearts in the untreated groups exhibited cardiac dysfunction, as evidenced by a decrease in LVDP and an increase in LVEDP (Figures 1 and 2, $P=.01$ ). Strikingly, treatment of the rats with $\mathrm{BH}_{4}$ attenuated $\mathrm{I} / \mathrm{R}$-induced myocardial dysfunction, as evidenced by preservation in LVDP and a minimal increase in LVEDP (Figures 1 and $2, P=.004$ ).

\section{Myocardial MDA levels}

MDA levels were measured in both groups of rats after I/R as an index of lipid peroxidation.7,10,11 After I/R, MDA levels increased in the myocardium (Figure 3); this effect was attenuated with $\mathrm{BH}_{4}$ treatment $(P=.01)$.

\section{Coronary Endothelial Function}

Coronary vascular reactivity to endothelium-dependent (acetylcholine) and endothelium-independent (SNP) vasodilatation was assessed in the left anterior descending artery after I/R. Global I/R resulted in endothelial dysfunction, as evidenced by diminished acetylcholine-mediated vasorelaxation $(P=.003)$. Endothelium-independent responses to SNP remained unchanged after $\mathrm{I} / \mathrm{R}$ (not shown). Importantly, treatment with $\mathrm{BH}_{4}$ improved acetylcholine responses, indicating a preservation of endothelial function after I/R (Figure 4, $P=.001$ ).

\section{Cardiomyocyte Cell Injury}

Figure 5 depicts the effects of simulated I/R on cellular injury (as assessed by trypan blue exclusion) in the presence or absence of $\mathrm{BH}_{4}(20 \mu \mathrm{mol} / \mathrm{L})$ added during reperfusion.

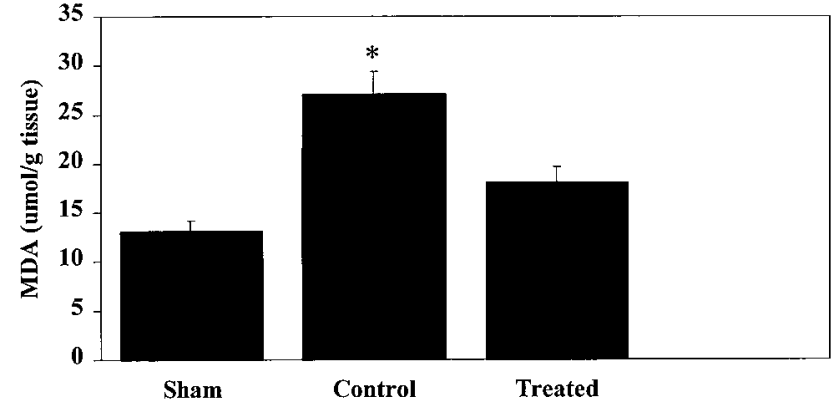

Figure 3. Myocardial MDA levels in the myocardium. In response to $I / R$, there was a significant increase in MDA levels. Treatment with $\mathrm{BH}_{4}$ attenuated MDA levels, a marker of lipid peroxidation. ${ }^{*} \boldsymbol{P}=.01$ versus control.

$\mathrm{I} / \mathrm{R}$ resulted in marked cardiomyocyte cell injury when compared with that seen in the nonischemic control group $(P=.001)$. This response was completely prevented with $\mathrm{BH}_{4}$ treatment $(P=.001)$.

\section{Discussion}

\section{Key Observations}

The following observations have been made in this study: (1) supplementation with the essential NOS cofactor $\mathrm{BH}_{4}$ improves functional recovery after global I/R; (2) I/Rinduced increases in myocardial MDA levels, an index of lipid peroxidation, are attenuated by $\mathrm{BH}_{4}$; (3) $\mathrm{BH}_{4}$ treatment restores impaired endothelial function in epicardial coronary arteries after global I/R; and (4) acute $\mathrm{BH}_{4}$ incubation exerts direct cardioprotective effects in human cardiomyocytes subjected to simulated I/R. These data underscore the importance of $\mathrm{BH}_{4}$ as a mediator of I/R injury and suggest that this cofactor might exert myocardial protection through 


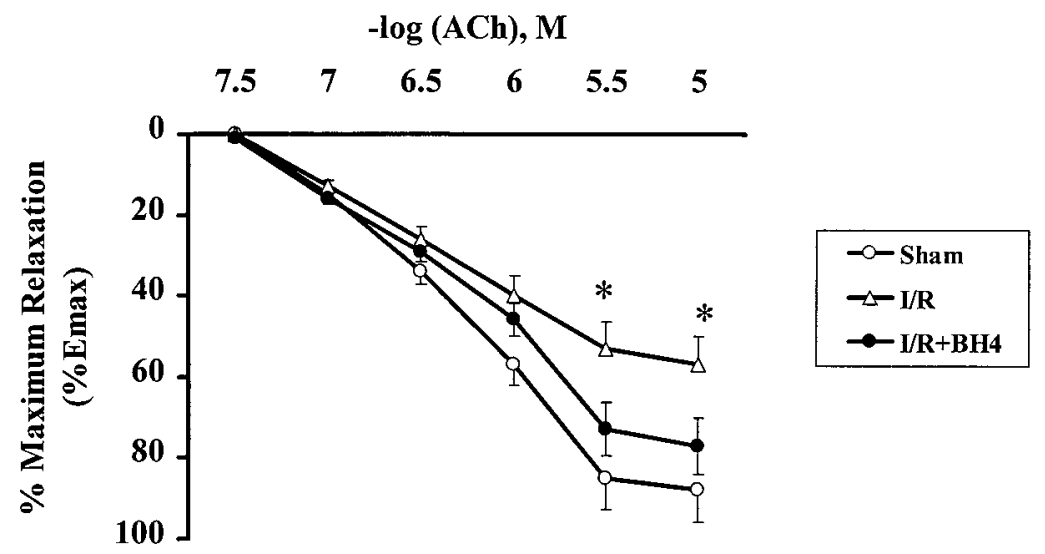

Figure 4. Coronary endothelial function assessment. Vascular responses to the endothelium-dependent vasodilator acetylcholine (Ach) were studied in segments of left coronary arteries precontracted with the $\mathrm{ED}_{75}$ of phenylephrine. $\mathrm{l} / \mathrm{R}$ resulted in endothelial dysfunction, and this response was prevented with $\mathrm{BH}_{4}$ treatment. ${ }^{*} \boldsymbol{P}=.003$ versus sham and $\mathrm{I} / \mathrm{R}+\mathrm{BH} 4$ groups.

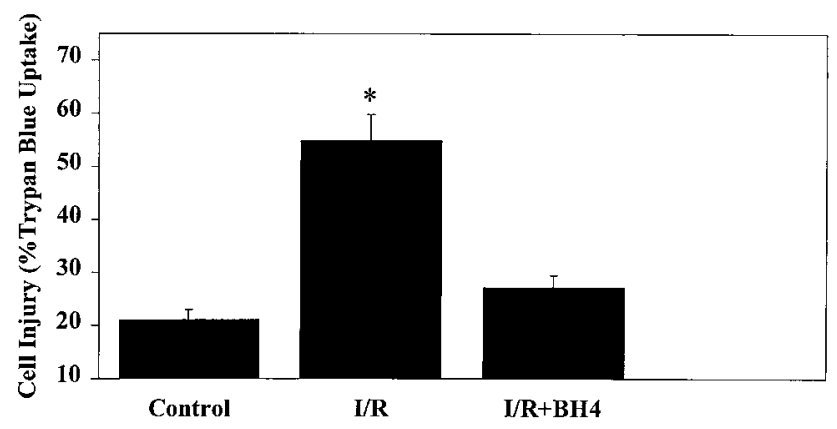

Figure 5. Cell injury, as assessed by means of trypan blue uptake, in human ventricular heart cells subjected to simulated I/R. $\mathbf{B H}_{4}$, when used as a prereperfusion strategy, completely prevented I/R-induced cardiomyocyte injury. ${ }^{*} \boldsymbol{P}=0.001$ versus nonischemic control.

prevention of endothelial dysfunction, lipid peroxidation, and direct cardiomyocyte injury.

\section{$\mathrm{BH}_{4}$ : An Emerging Cardiovascular Target}

In the endothelial cell NO is synthesized from L-arginine by NO synthase (endothelial NOS or NOS III). $\mathrm{BH}_{4}$ is an essential cofactor required for the activation of NOS and the production of NO. Mechanistically, $\mathrm{BH}_{4}$ functions as a reducing cofactor, transferring electrons to the enzymebound L-arginine. ${ }^{1,12}$ Furthermore, it promotes stabilization of the dimeric (active) form of NOS and also increases the affinity of NOS for L-arginine. Additionally, in the presence of low levels of $\mathrm{BH}_{4}$, NOS functions as a reduced nicotinamide adenine dinucleotide phosphate oxidase, resulting in the production of oxygen-derived free radicals instead of
NO. ${ }^{1}$ Thus decreased levels of $\mathrm{BH}_{4}$ might lead to diminished NO production, enhanced NO breakdown, or both. Decreased availability of $\mathrm{BH}_{4}$ has now been implicated as a pathogenic factor causing endothelial dysfunction in a variety of cardiovascular disease states. Likewise, acute and chronic supplementation with $\mathrm{BH}_{4}$ has been demonstrated to improve endothelium-dependent vasomotion clinically and experimentally. ${ }^{1-3,5}$

Accumulating evidence suggests that modulation of the L-arginine-NO pathway might exert cardioprotective effects after I/R. ${ }^{13-15}$ Previous studies, including work from our group, ${ }^{15}$ have demonstrated that L-arginine supplementation exerts cardioprotective effects by means of increasing NO production. Given the importance of $\mathrm{BH}_{4}$ in the regulation of NOS, we set out to determine whether exogenous supplementation of this cofactor would enhance functional recovery and endothelial function in an experimental model of global I/R. In addition, we tested the hypothesis that $\mathrm{BH}_{4}$ exerts direct cardioprotective effects (independent of endothelial cells) in human ventricular cardiomyocytes subjected to $\mathrm{I} / \mathrm{R}$.

\section{Potential Mechanisms of $\mathrm{BH}_{\mathbf{4}}$ Cardioprotection}

$\mathrm{I} / \mathrm{R}$ injury incites an acute inflammatory response that affects the structure, function, and metabolism of the endothelium and cardiomyocyte. The cellular element of the microvasculature that appears to be most affected by $I / R$ is the endothelium. Ischemia is known to alter the membrane potential, increase intracellular volume, and impair cytoskeletal organization of the endothelial cell. ${ }^{16}$ From a functional standpoint, endothelium-dependent vasodilatation is impaired, ${ }^{17-19}$ whereas the responses to endothelium- 

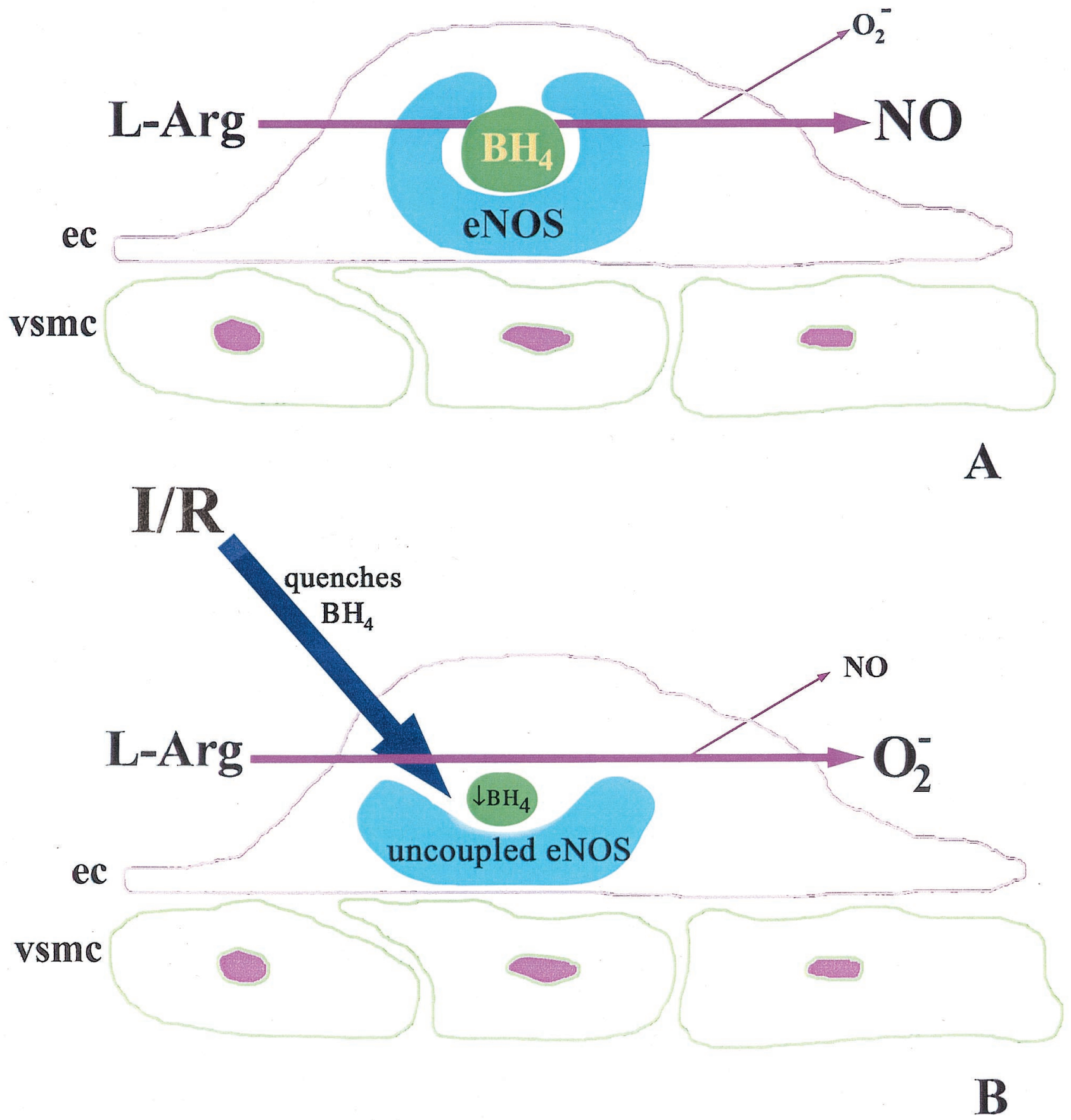

Figure 6. Top, $\mathrm{BH}_{4}$ is a critical cofactor for endothelial NOS (eNOS). In the presence of adequate amounts of $\mathrm{BH}_{4}$, NOS is coupled and produces mainly NO and small amounts of superoxide. Bottom, I/R might directly impair $\mathrm{BH}_{4}$ bioavailability. This results in an uncoupling of NOS, with a resultant increase in superoxide versus NO production. $\mathrm{BH}_{4}$ supplementation might represent a novel cellular target for future operative myocardial protective strategies. L-arg, L-arginine; ec, endothelial cell; vsmc, vascular smooth muscle cell.

derived contracting factors are exaggerated after I/R. Endothelial dysfunction occurs rapidly during reperfusion and sets the stage for leukocyte-endothelial cell interaction, an important factor in the pathophysiology of $I / R$ injury. The generation of oxygen-derived free radicals is also an important mechanism of I/R injury. Dysfunctional endothelium and activated neutrophils are important sources of oxidants, such as superoxide anion. Under normal conditions, the flux 
of NO greatly exceeds the rate of superoxide production. This allows NO to effectively scavenge the low intracellular levels of superoxide, repel neutrophil adhesion, and exert endothelium-dependent vasodilatation. However, within minutes of reperfusion, the balance between $\mathrm{NO}$ and superoxide generation is altered in favor of the latter. In addition to enhanced potential for oxygen radical generation, postischemic hearts might exhibit a decrease in the tissue concentration of intracellular oxidant scavengers, which might further predispose to myocardial damage.

The beneficial effects of $\mathrm{BH}_{4}$ observed in the present studies likely result from the production of $\mathrm{NO}$, a correction of reperfusion-induced changes in superoxide-NO balance, or both (Figure 6). Both decreased NO production and increased superoxide anion release are well-known inhibitors of endothelial function. Therefore the improvements in endothelial function might have resulted from either one of these mechanisms or a collective effect on both pathways. In an experimental model of global $\mathrm{I} / \mathrm{R}$, we present evidence to suggest that $\mathrm{BH}_{4}$ might augment functional recovery after $\mathrm{I} / \mathrm{R}$ by preventing coronary endothelial dysfunction and decreasing MDA, a product of lipid peroxidation and index of tissue injury. However, data from our human heart cell model suggest that $\mathrm{BH}_{4}$ might exert direct cardiomyocyte protection independent of the presence of endothelial cells, neutrophils, platelets, or fibroblasts. The ability of $\mathrm{BH}_{4}$ to exert direct cardioprotective effects in the absence of endothelial cells might appear atypical at first; however, we have recently observed similar direct cardioprotective effects of $\mathrm{L}$-arginine and NO donors in this model of simulated I/R. ${ }^{15}$ In addition, evidence from our research group suggests that NO might attenuate cardiomyocyte injury by opening of $\mathrm{K}_{\mathrm{ATP}}$ channels in a cyclic guanosine monophosphatedependent fashion. Hence it is possible that through improving $\mathrm{NO}$ production-balance, $\mathrm{BH}_{4}$ exerts cardioprotective effects similar to those noted previously with L-arginine. The mechanism of injury in the Langendorff and in vitro cell-culture preparation might be more weighted toward oxidant injury, and hence $\mathrm{BH}_{4}$ should be tested in an in vivo model in which both mechanisms and their interactions are engaged.

An important question that merits some discussion relates to the potential clinical applicability of L-arginine versus $\mathrm{BH}_{4}$ as therapeutic strategies for modulating NOmediated cardioprotection. Although low-dose L-arginine and $\mathrm{BH}_{4}$ might function in a very similar fashion in terms of their cardioprotective effects, the dose-response relationship for L-arginine is narrow; higher doses of L-arginine might actually exaggerate cardiomyocyte injury through excessive NO production (Weisel RD, unpublished observations). We believe that one of the primary abnormalities after $\mathrm{I} / \mathrm{R}$ is a decrease in $\mathrm{BH}_{4}$ levels. Several biochemical studies have demonstrated that activation of NOS in the presence of suboptimal $\mathrm{BH}_{4}$ concentrations results in uncoupling of oxygen reduction and arginine oxidation, with the resultant formation of superoxide anion and hydrogen peroxide. ${ }^{12,20-22}$ Hence NOS might become a source of oxygenderived free radicals in the face of low levels of this cofactor, and there is strong evidence to support this conclusion in vitro. ${ }^{12,20-24}$ Treatment with $\mathrm{BH}_{4}$ might therefore serve to restore the NO-superoxide anion balance without the deleterious effects of excess $\mathrm{NO}$ production observed with highdose L-arginine administration. $\mathrm{BH}_{4}$ has very low toxicity and can be administered intravenously in high doses. ${ }^{25}$

\section{Critique of the Human Ventricular Heart Cell Model}

A critique of the model of simulated $\mathrm{I} / \mathrm{R}$ is provided. The heart cells used in these studies have been extensively evaluated in previous reports. These myocytes retain many characteristics of freshly isolated cells but have distinct differences. These cells become quiescent after enzymatic digestion and passaging. Despite an abundant supply of mitochondria and contractile proteins, the sarcomeres become disrupted during division and do not reestablish their characteristic functional format. However, the metabolic response of these cells after ischemia is similar to our intraoperative findings during cardiac operations. ${ }^{26-28}$ Furthermore, the cellular concentrations of troponin I, troponin $\mathrm{T}$, and creatine kinase MB isoform are similar to those seen in vivo. Although the molecular and biochemical natures of these cells resemble those of in vivo cardiomyocytes, these cells undergo a partial phenotypic change, become quiescent, and regain their ability to divide. Other investigators have shown that senescent rat cardiomyocytes might also regain their ability to divide in culture. Therefore despite their quiescent state, we believe that these cells are phenotypically cardiomyocytes, retain many characteristics of normal human myocardium, and might simulate the human heart during cardioplegic arrest.

\section{Limitations and Future Studies}

A few limitations of these studies must be acknowledged to facilitate objective evaluation of these data. First, we do not provide an assessment of NO production or NO-superoxide anion balance in the present study. Although these represent well-known actions of $\mathrm{BH}_{4}$, such measurements would have strengthened our conclusions. Our data suggest that the addition of this cofactor reduces oxidative stress and improves NO-mediated vasodilatation to acetylcholine. This is indirect evidence that $\mathrm{BH}_{4}$ restores the balance between $\mathrm{NO}$ and reactive oxygen species after I/R. Second, other mechanisms of I/R injury were not assessed, particularly neutrophil activation or reactive oxygen species production. Third, 
we did not measure the circulating levels of $\mathrm{BH}_{4}$. This remains a challenging assay that is only available at a few centers in the world; however, the concentrations of $\mathrm{BH}_{4}$ used have been previously demonstrated to result in increased plasma levels in rats. Fourth, it would have been nice to have confirmatory measurements of lactate dehydrogenase, creatine kinase, or troponin release from isolated human cardiomyocytes to support the results of the trypan blue uptake assay. Finally, the animal studies were conducted after 7 days of treatment with $\mathrm{BH}_{4}$. No data are available on acute treatment with $\mathrm{BH}_{4}$, except for the in vitro cell-culture experiments.

Clearly, the most convincing evidence for $\mathrm{BH}_{4}$ as a mediator of $\mathrm{I} / \mathrm{R}$ would come from experiments conducted in the setting of cofactor deficiency. Recently, a $\mathrm{BH}_{4}$-deficient mouse has been described. ${ }^{12,29}$ The hyperphenylalaninemic mouse mutant (hph-1) displays 90\% deficiency in guinane triphosphate cyclohydrolase I, the rate-limiting step in the synthesis of $\mathrm{BH}_{4}$. We are currently conducting studies to examine whether global I/R injury is exaggerated in hph-1, $\mathrm{BH}_{4}$-deficient mice.

\section{Conclusions}

Supplemental $\mathrm{BH}_{4}$ exerts a novel cardioprotective effect on left ventricular function, endothelial-vascular reactivity, oxidative damage, and cardiomyocyte injury after $\mathrm{I} / \mathrm{R}$ and might represent an important cellular target for future operative myocardial-protection strategies. We suggest that a relative deficiency of $\mathrm{BH}_{4}$ might occur during $\mathrm{I} / \mathrm{R}$, which might shift the balance between NOS-catalyzed NO production and superoxide anion generation; this cellular mechanism is restored with cofactor therapy.

\section{References}

1. Katusic ZS. Vascular endothelial dysfunction: does tetrahydrobiopterin play a role? Am J Physiol. 2001;281:H981-6.

2. Verma S, Lovren F, Dumont AS, Mather K, Maitland A, Kieser TM, et al. Tetrahydrobiopterin improves endothelial function in human saphenous veins. J Thorac Cardiovasc Surg. 2000;120:668-71.

3. Schmid RA, Hillinger S, Walter R, Zollinger A, Stammberger U, Speich R, et al. The nitric oxide synthase cofactor tetrahydrobiopterin reduces allograft ischemia-reperfusion injury after lung transplantation. J Thorac Cardiovasc Surg. 1999;118:726-32.

4. Jiang J, Valen G, Tokuno S, Thoren P, Pernow J. Endothelial dysfunction in atherosclerotic mice: improved relaxation by combined supplementation with L-arginine-tetrahydrobiopterin and enhanced vasoconstriction by endothelin. Br J Pharmacol. 2000;131:1255-61.

5. Hillinger S, Sandera P, Carboni GL, Stammberger U, Zalunardo M, Schoedon G, et al. Survival and graft function in a large animal lung transplant model after $30 \mathrm{~h}$ preservation and substitution of the nitric oxide pathway. Eur J Cardiothorac Surg. 2001;20:508-13.

6. Ohkawa H, Ohishi N, Yahi K. Assay for lipid peroxides in animal tissues by thiobarbituric acid reaction. Anal Biochem. 1979;95:351-8.

7. Chen H, Zhang YC, Li D, Phillips I, Mehta P, Shi M, et al. Protection against myocardial dysfunction induced by global ischemia-reperfusion by antisense-oligodeoxynucleotides directed at $\beta_{1}$-adrenoceptor mRNA. J Pharmacol Exp Ther. 2000;294:722-7.
8. Tumiati LC, Mickle DAG, Weisel RD, Williams WG, Li RK. An in-vitro model to study myocardial ischemic injury. J Tissue Cult Methods. 1994;16:1-9.

9. Ikonomidis JS, Tumiati LC, Weisel RD, Mickle DAG, Li RK. Preconditioning human ventricular cardiomyocytes with brief periods of simulated ischemia. Cardiovasc Res. 1994;28:1285-91.

10. Kokita N, Hara A, Abiko Y, Arakawa J, Hashizume H, Namiki A. Propofol improves functional and metabolic recovery in ischemiareperfused isolated rat hearts. Anesth Analg. 1998;86:252-8.

11. Ozden A, Aybek Z, Saydam N, Calli N, Sauda, O, Duzcan E, et al. Cytoprotective effect of trimentazidine on $75 \mathrm{~min}$ renal ischemiareperfusion injury in rats. Eur Surg Res. 1998;30:227-34.

12. Cosentino F, Barker JE, Brand MP, Heales SJ, Werner ER, Tippins JR, et al. Reactive oxygen species mediate endothelium-dependent relaxations in tetrahydrobiopterin-deficient mice. Arterioscler Thromb Vasc Biol. 2001;21:496-502.

13. Weurocj AS. Ma XL, Lefer AM. The role of L-arginine in ameliorating reperfusion injury after myocardial ischemia in the cat. Circulation. 1992;86:279-88.

14. Sato K, Zhao ZQ, McGee DS, Williams MW, Hammon JW, VintenJohansen J. Supplemental L-arginine during cardioplegic arrest and reperfusion avoids regional post-ischemic injury. J Thorac Cardiovasc Surg. 1995;110:302-14.

15. Shiono N, Rao V, Weisel RD, Kawasak M, Li RK, Mickle DAG, et al. Effects of L-arginine in a human heart cell model of ischemia and reperfusion. Am J Physiol. 2002;282:H805-15.

16. Carden DL, Granger DN. Pathophysiology of ischemia-reperfusion injury. J Pathol. 2000;190:255-66.

17. Banda MA, Lefer DJ, Granger DN. Postischemic endothelium-dependent vasodilatation is preserved in adhesion molecule deficient mice. Am J Physiol. 1997;273:H2721-5.

18. Harrison DG. Cellular and molecular mechanisms of endothelial cell dysfunction. J Clin Invest. 1997;100:2153-7.

19. Granger DN. Physiology and pathophysiology of the microcirculation. Prog Cardiovasc Med. 1998;3:123-40.

20. Pou S, Pou WS, Bredt DS, Synder SH, Rosen GM. Generation of superoxide by purified brain nitric oxide synthase. J Biol Chem. 1992;267:24173-6.

21. Vasquez-Vivar J, Kalyanaraman B, Martasek P, Hogg N, Masters BSS, Karoui H, et al. Superoxide generation by endothelial nitric oxide synthases: the influence of cofactors. Proc Natl Acad Sci U S A. 1998;95:9220-5.

22. Cosentino F, Katusic ZS. Tetrahydrobiopterin and dysfunction of endothelial nitric oxide synthase in coronary arteries. Circulation. 1995;91:139-44.

23. Heinzel B, John M, Klatt P, Bohme E, Mayer B. Ca $++/$ calmodulin dependent formation of hydrogen peroxide by brain nitric oxide synthase. Biochem J. 1992;281:627-30.

24. Kinoshita H, Milstein S, Wambi C, Katusic ZA. Inhibition of tetrahydrobiopterin biosynthesis impairs endothelium-dependent relaxations in canine basilar arteries. Am J Physiol. 1997;42:H718-24.

25. Walter R, Blau N, Schaffner A, Schneemann M, Speich R, Stocker R, et al. Inhalation of nitric oxide cofactor tetrahydrobiopterin in health volunteers. Am J Respir Crit Care Med. 1997;156:2006-10.

26. Hayashida N, Weisel RD, Shirai T, Ikonomidis JS, Ivanov J, Carson SM, et al. Tepid antegrade and retrograde cardioplegia. Ann Thorac Surg. 1995;59:723-9.

27. Hayashida N, Ikonomidis JS, Weisel RD, Shirai T, Ivanov J, Carson $\mathrm{S}$, et al. Adequate distribution of warm cardioplegic solution. J Thorac Cardiovasc Surg. 1995;110:800-12.

28. Shirai T, Rao V, Weisel RD, Ikonomidis JS Hayashida N, Ivanov J, et al. Antegrade and retrograde cardioplegia: simultaneous or alternate? J Thorac Cardiovasc Surg. 1996;112:787-96.

29. McDonald JD, Bode VC. Hyperphenylalaninemia is the hph-1 mouse mutant. Pediatr Res. 1988;23:63-7.

\section{Discussion}

Dr David Follette (Sacramento, Calif). I have had an interest in I/R for more than 25 years. Although cardioprotective 
strategies have been perfected during this period of time, we only recently have begun to understand the complex molecular interactions that are involved in I/R injury. Earlier in this meeting, we heard how cyclosporine and FK-506 provide protection against I/R by means of calcineurin inhibition. Many of the contributions that have enhanced our understanding of this complex topic have been made by Dick Weisel and the Toronto group. Today's study, so nicely presented by Dr Verma, continues this fine tradition.

We now know that the severity of reperfusion injury is related to the complex interactions between the endothelial cell and the cardiac myocyte. As has been shown by Dr Verma today, I/R leads to an imbalance of NO and superoxide generation. This then results in endothelial cell dysfunction and tissue destruction. It appears that the cofactor $\mathrm{BH}_{4}$ was shown to modify this reaction.

I have several questions for Dr Verma. How did you select the 7-day pretreatment period in your animals?

Dr Verma. Thank you, Dr Follette, for your kind comments.

The 7-day treatment was based on a previous study in which treating rats at $25 \mathrm{mg} \cdot \mathrm{kg}^{-1} \cdot \mathrm{d}^{-1}$ for 7 days results in a 3 -fold increase in the plasma $\mathrm{BH}_{4}$ levels. We used that as an index of loading. Unfortunately, we did not measure $\mathrm{BH}_{4}$ in this study.

Dr Follette. That then leads into the next question. Can you give us your thoughts on the mechanism of how exogenous supplementation works?

Dr Verma. $\mathrm{BH}_{4}$ may provide protection from ischemia and reperfusion by interactions with both the endothelial cell and cardiomyocyte. In the endothelial cell, $\mathrm{BH}_{4}$ serves as a key reducing cofactor, facilitating coupling of eNOS into a predominantly NO (vs superoxide) producing enzyme. This, in turn, results in improvement in endothelial function, a key component of reperfusion injury. Our data also demonstrate that $\mathrm{BH}_{4}$ exerts direct cardiomyocyte protection, independent of other cell types. This may be related to augmented cardiomyocyte NO production, which we have previously demonstrated to be an important mediator of mitochondrial potassium channel opening in human cardiomyocytes. Opening of these channels results in intramitochondrial depolarization and augmented cellular respiration, with resultant decreases in intracellular calcium.

Dr Follette. Do you believe then that ischemia causes the $\mathrm{BH}_{4}$ levels to drop acutely?

Dr Verma. Yes, and actually there are other studies in lung ischemia models that have demonstrated diminished $\mathrm{BH}_{4}$, although not in a cardiac I/R model.

Dr Follette. Is it possible then that $\mathrm{BH}_{4}$ does not have much to do with reperfusion but rather induces ischemic tolerance?

Dr Verma. Clearly I think the evidence so far in the literature supports the concept that the greatest damage occurs to the endothelium during the reperfusion phase. We do not have data on $\mathrm{BH}_{4}$, but if you compare the effects on coronary endothelial function between ischemia and I/R, clearly the reperfusion component is much higher than that of the ischemia component in terms of impairment in acetylcholine responses. I do believe that $\mathrm{BH}_{4}$ is helping the reperfusion phase. I think we are raising the levels to a supranormal level, and that reserve is decreasing superoxide and, through that mechanism, preventing cardiac dysfunction and endothelial dysfunction. It is a hard question to answer in the absence of NO and superoxide measurements. I think we will have those measurements in the next few months.

Dr Follette. Perhaps you have already partially answered it earlier when you stated that when you gave the $\mathrm{BH}_{4}$ acutely it did not have the same effects as the pretreated, and therefore perhaps it is inducing some form of tolerance rather than necessarily affecting the reperfusion process.

Dr Verma. This is possible. The other point is that these are normal rats. Probably the results would be different or more dramatic in dysfunctional hearts.

Dr Follette. Lastly, the use of the cardiac myocyte model is intriguing, and I was especially impressed with your critique of the method in your article. Can you speculate on how $\mathrm{BH}_{4}$ can provide direct myocyte protection independent of endothelial cell function, which we have always assumed was NO's primary site of action.

Dr Verma. Recently, we examined the effects of L-arginine and other agents, NO donors, on cardiomyocytes (independent of endothelial cells). Agents that increase NO independent of endothelial cells afford protection in the cardiomyocyte model by opening potassium channels in the mitochondria. That is the mechanism that has been proposed. As you know, NO can stimulate cyclic guanosine monophosphate, which facilitates the opening of potassium channels.

Dr Michael Mulligan (Seattle, Wash). I have just a couple of comments. I think that your hypothesis about how this compound is potentially working is very interesting, but we have to be careful in interpreting that. I think that your results are not surprising given the fact that we have seen this already in the pig heart from the group at Texas A\&M back in 1996, but $\mathrm{BH}_{4}$ is also known to be an oxygen radical scavenger in and of itself, and therefore it could be having very nonspecific functions as they relate to NO physiology. We have to be careful whether we think that it is working by stabilizing endothelial NOS, such that we produce more NO, and that is somehow protective. Excess NO is toxic to endothelial cells, and in fact, $\mathrm{BH}_{4}$ has been shown to be protective against NO-induced endothelial toxicity. It has also been shown in 2 articles that relate to lung injury (one of them to ischemic lung injury) that $\mathrm{NO}$ is injurious to the lung, and $\mathrm{BH}_{4}$ has also been shown to potentiate neuronal toxicity in ischemic brain injury.

I think there is more to this story. There might be something specific about the isoenzyme system in the heart, and it might rely on a balanced stimulation of endothelin A and B receptors that relates to NO physiology in ways that we do not understand.

I have been working with $\mathrm{NO}$ as it relates to acute lung injury since 1990, and I still cannot stand up and say it is all good or it is all bad, and I cannot explain to you how modulation of endothelial NOS activity is so discretely going to result in production of excessive and injurious peroxynitrite or protective NO.

It is a very elegant study, but I just would advise you from experience that we have to be careful in the way that we interpret these things.

Dr Verma. Now, in response to your question about the pig injury model, no functional data were provided in that study. They did demonstrate that in the pig heart subjected to $\mathrm{I} / \mathrm{R}, \mathrm{BH}_{4}$ acutely 
improves endothelial function. I do not know of any cardiac functional data available except those from this study.

Your question about NO being toxic in terms of function is an important one, and clearly our group has demonstrated that Larginine in higher doses may impair contractility. Probably we should just be using a cofactor that does not stimulate NO pro- duction already but restores the balance between $\mathrm{NO}$ and superoxide. I personally believe that a combination of low doses of L-arginine and $\mathrm{BH}_{4}$ may work out to be ideal; however, this hypothesis remains to be tested. However, your comments are very well taken, and the precarious balance between the actions of NO on the heart must be kept in mind. 